\title{
Tìm kiếm giải pháp cho vấn đề rác thải nhựa toàn cầu
}

\author{
Nguyễn Thị Mỹ Hiền, Hà Thị Hồng Hạnh \\ Đại học Kinh tế Quốc Dân \\ Đồng Tâm, Hai Bà Trưng, Hà Nội \\ Khoa Luật, Đại học Quốc gia Hà Nội
}

Ngày 24 tháng 1 năm 2022

Preprint DOI: https://osf.io/d5rxu

\section{Thực trạng về chất thải nhựa hiện nay}

Nhựa là một trong những vật liệu được sử dụng rộng rãi, phổ biến nhất trên toàn cầu và mang lại sự thoải mái, tiện lợi và an toàn cho cuộc sống của con người. Cùng với cuộc sống ngày càng bận rộn, nhu cầu về mọi việc nhanh gọn và tiện lời ngày càng tăng do đó những đồ nhựa ngày càng được ưa chuộng sử dụng hơn, dẫn đến tình trạng hàng triệu tấn rác thải nhựa thải ra mỗi năm trên toàn cầu, gây ảnh hưởng trực tiếp đến môi trường và đời sống con người. Theo một ước tính gần đây cho thấy rằng, từ năm 1950 đến năm 2015, khoảng 6300 triệu tấn chất thải nhựa được tạo ra, trong đó chỉ có khoảng 600 triệu tấn (9\%) đã được tái chế, 800 triệu tấn (12\%) được đốt và khoảng 4900 - $79 \%$ được tích tụ trong các bãi chôn lấp hoặc trong môi trường tự nhiên (Geyer et al., 2017). Với tỷ lệ tái chế lại tương đối thấp như vậy, đã gây lãng phí nhiều nguồn tài nguyên cho các nhà sản xuất đồng thời lượng tồn đọng nhiều trong môi trường đã gây ra đòn tàn phá trực tiếp đến con người và sinh vật. Tình trạng ô nhiễm chất thải nhựa ngày càng trở nên đáng báo động trên toàn cầu.

Trước tình trạng đó, có 2 cách chính để đối phó với ô nhiễm chất thải nhựa: quản lí trong nước và xuất khẩu (Wen et al., 2021). Do những rủi ro về môi trường và lợi ích kinh tế mang lại, dòng chảy buôn bán chất thải nhựa toàn cầu từ các nước giàu sang các nước nghèo để xử lí đã trở nên rộng rãi kể từ những năm 1990 (Qu et al., 2019). Tuy nhiên, việc buôn bán chất thải nhựa toàn cầu mới chỉ nổi cộm lên trong những năm gần đây, sau khi Trung Quốc 
tuyên bố lệnh cấm nhập khẩu rác thải từ nước ngoài vào năm 2017. Vậy dưới đây sẽ tìm hiểu rõ hơn về thương mại chất thải nhựa toàn cầu.

\section{Thực trạng thương mại chất thải nhựa toàn cầu}

Trung Quốc là quốc gia nhập khẩu chất thải nhựa lớn nhất thế giới. Trước khi có lệnh cấm, lượng rác thải nhựa nhập khẩu hàng năm của Trung Quốc đạt 8,88 triệu tấn, với 70,6\% được chôn lấp hoặc thậm chí không được quản lý, gây ra các vấn đề nghiêm trọng về môi trường (Wen et al., 2021). Để giảm thiểu tình trạng này, tháng 1 năm 2018, Trung Quốc ra chính sách "Thanh Kiếm Quốc Gia", tuyên bố cấm nhập khẩu 24 loại rác thải rắn từ nước ngoài, bao gồm cả rác thải nhựa (Katz, 2019). Lệnh cấm đột ngột này đã làm đứt gãy dòng chảy buôn bán chất thải nhựa toàn cầu cũng như các hệ thống và cơ chế xử lý rác thải nhựa ở nhiều quốc gia. Theo đó, năm 2018, dòng chảy buôn bán chất thải nhựa toàn cầu giảm mạnh $45.5 \%$ so với mức cơ bản (Wen et al., 2021). Các nước xuất khẩu rác thải nhựa chính sang Trung Quốc như Mỹ, Canada, châu Âu và thậm chí là Nhật Bản, Hàn Quốc hoang mang không biết liệu lượng rác thải của mình sẽ đến đâu. Điều này cho thấy thiếu sự quản lí chất thải nhựa chính thức ở các quốc gia khiến không thể tự " tiêu hóa" được lượng chất thải trong nội bộ. Một mặt, các quốc gia bắt đầu ý thức được tìm kiếm các giải pháp mới, để thúc đẩy công nghệ chế biến rác thải nhựa. Mặt khác, họ lại tiếp tục tìm kiếm các nước mới nơi họ có thể vận chuyển chất thải sang đó để giảm lượng chất thải trong nước.

Sau lệnh cấm của Trung Quốc, Đông Nam Á bị ảnh hưởng đáng kể nhất. Hàng ngàn contarner chứa đầy rác thải nhựa được chuyển hướng đến các nước Đông Nam Á như Thái Lan, Việt Nam, Malaysia điều này đã khiến nơi đây nhanh chóng trở nên choáng ngợp trước khối lượng rác khổng lồ (PV., 2018; Quynh, 2020; TTXVN, 2022) Theo thống kê của Hiệp hội các quốc gia Đông Nam Á (ASEAN), khu vực "đã trải qua sự gia tăng 171\% về nhập khẩu chất thải nhựa từ 836.529 tấn năm 2016 lên 2.231 .127 tấn vào năm 2018 (Greenpeace Southeast Asia, 2019). Đứng trước áp lực lớn từ lượng rác thải được điều hướng vào từ nước ngoài sau khi Trung Quốc ngừng nhập khẩu như vậy, chính phủ các nước như Việt Nam, Malaysia và Thái Lan đã cố gắng kiểm soát chặt chẽ hơn việc nhập khẩu phế liệu từ năm 2018.

\section{Tác hại từ thương mại chất thải nhựa toàn cầu}

Mặc dù hầu hết nhựa có thể tái chế và ở một mức độ nào đó có thể giảm thiểu sự thiếu hụt tài nguyên ở các nước đang phát triển, tuy nhiên, nó đã gây ra các tác động môi trường đáng kể từ quá trình buôn bán và xử lí, chưa kể đến 
rác thải nhựa có thể chứa các chất độc hại. Do đó, việc vận chuyển rác thải nhựa từ quốc gia này sang quốc gia khác cũng mang đến nhiều hệ lụy.

Trước hết, nếu như việc xuất - nhập khẩu mà không có sự đồng thuận của cả 2 bên, người nhận bị "ép" nhận mà không có đủ tiềm lực để xử lý rác thải, người gửi cũng chỉ vứt ra đấy, không quan tâm đến rác thải của mình được xử lý như thế nào, bỏ mặc cho người dân ở nơi nhận sống trong môi trường mất vệ sinh, ngập trong rác thải. Bên cạnh đó, còn có sự lỏng lẻo trong công tác quản lý, rà soát của cơ quan hành chính và các hoạt động tái chế rác thải bất hợp pháp ở nước nhận rác cũng gây ra những hậu quả đáng quan ngại đối với cuộc sống của người dân cũng như môi trường xung quanh đó.

Tiếp theo, iệc vận chuyển chất thải từ những nước có thu nhập cao sang những nước có thu nhập thấp, càng làm mất an ninh môi trường các nước nghèo. Đặc biệt những người dân ở tầng đáy xã hội, họ bị vùi dập, bỏ mặc trong những đống rác thải độc hại, mất vệ sinh mà không phải do họ tạo ra. Sức khỏe con người cũng như tính mạng đang ngày càng xuống cấp do phải tiếp xúc nhiều với rác thải cũng như môi trường đang bị xuống cấp trầm trọng.

Bên cạnh đó, tình trạng vận chuyển rác thải từ các nước giàu sang các nước nghèo để xử lí hộ, còn mang đậm tính chất "chủ nghĩa thục dân" - để các nước nghèo gồng gành những gánh nặng độc hại của những nước giàu.

\section{Những nỗ lực trong việc cắt giảm thương mại chất thải nhựa toàn cầu}

Được xem là một trong những giải pháp để đối phó với ô nhiễm rác thải nhựa, tuy nhiên, nếu nó không có những quy tắc chung cũng như các chính sách, chiến lược quản lí rác thải chặt chẽ ở mỗi quốc gia thì hàng tá hệ lụy về môi trường, sức khỏe con người trên toàn cầu sẽ khó tránh khỏi, nhất là các nước nghèo, đang phát triển. Việc Trung Quốc đưa ra lệnh cấm, đã đưa ra một hồi chuông cảnh tỉnh cho tất cả các quốc gia trên thế giới, đồng thời thúc đẩy những tổ chức quốc tế tham gia vào điều tiết, đưa ra những quy định chung để kiếm soát dòng thải toàn cầu một cách kịp thời.

Tháng 5/2019, trước tình hình cấp bách đó, Liên Hợp Quốc và 181 nước thành viên đã họp bàn và đồng thuận đưa rác thải nhựa vào phạm vi kiểm soát của Hiệp ước Basel, với mục tiêu tăng cường kiểm soát các hoạt động vận chuyển xuyên biên giới của chất thải nhựa, các quốc gia xuất khẩu phải được sự đồng ý của bên nhập khẩu mới được vận chuyển qua, cấm xuất khẩu các loại chất thải nhựa nhiễm bẩn, độc hại và khó tái chế (Convention, 2019). Mặc dù sửa đổi Công ước Basel mới chỉ áp dụng cho khía cạnh thương mại của vấn đề nhựa rộng hơn, nhưng Công ước là một bước quan trọng trong 
việc đảo ngược thương mại nhựa hiện có giữa các nước giàu và nghèo, đang phát triển.

\section{Văn hóa môi trường là giải pháp giúp giải quyết vấn đề rác thải nhựa}

Để giải quyết vấn để chất thải nhựa (ô nhiễm rác thải nhựa), con người cần thực hiện hệ giải pháp đồng thời (mục tiêu cộng hưởng). Tuy nhiên gốc của giải pháp là văn hóa môi trường (Khuc, 2021a; Q. H. Vuong, 2021).

Văn hóa môi trường ở đây là từ nhận thức đến hành động gắn với bảo vệ môi trường, nhưng cốt lõi là tạo giá trị thặng dư sinh thái. Theo nguyên lý bán dẫn, văn hóa môi trường được coi là văn hóa thứ 11 của nhân loại $(\mathrm{Q}$. $\mathrm{H}$. Vuong, 2021).

Để mọi người thấm và thực hành văn hóa môi trường, con người cần sử dụng khung văn hóa để chuyển đổi. Khung văn hóa môi trường là một chu trình khép kín từ nhận thức đến hành động trải nghiệm, hưởng thụ và đóng góp vào môi trường (Khuc, 2021b). Sử dụng hệ xử lý thông tin 3D (Vuong, Q.H., 2022), con người có thể thực hiện quá trình chuyển đổi văn hóa môi trường hiệu quả.

Tóm lại, rác thải nhựa là vấn đề lớn của nhân loại, gây ra tác động môi trường và sức khỏe của con người trên toàn cầu và vì thế nhân loại cần chung nhận thức, cùng hành động (Q.-H. Vuong, 2021). Sự đầu tư cho khoa học (Q. H. Vuong, 2018), tăng cường thông tin truyền thông về tác động của rác thải nhựa lên con người, tăng cường sự hợp tác của các cơ quan giáo dục, nghiên cứu, tổ chức môi trường, các chuyên gia đầu ngành là những yếu tố sẽ góp phần tìm ra các giải pháp sáng tạo giúp giải quyết vấn đề này.

\section{Tài liệu tham khảo}

Convention, B. (2019). Basel Convention Plastic Waste Amendments. O, 8426.

Geyer, R., Jambeck, J. R., \& Law, K. L. (2017). Production, use, and fate of all plastics ever made. Science Advances, 3(7), 3-8. https://doi.org/10.1126/sciadv.1700782

Greenpeace Southeast Asia. (2019). Policy Brief : Southeast Asia 's struggle against the plastic waste trade. 4.

Katz, C. (2019). Piling Up: How China's Ban on Importing Waste Has Stalled Global Recycling. Yale Environment 360, 9.

Khuc, Q. Van. (2021a). Environmental culture thoughts to make a better world for our nature and children. OSF Preprints. https://doi.org/10.31219/osf.io/g5zex 
Khuc, Q. Van. (2021b). Khucc tower: from cultural values to practical solutions. Working Paper, 2021.

PV. (2018). Trung Quốc cấm nhập rác thải, Việt Nam đối mặt với nguy co trở thành " bãi rác của thế giới ". 3.

Qu, S., Guo, Y., Ma, Z., Chen, W. Q., Liu, J., Liu, G., Wang, Y., \& Xu, M. (2019). Implications of China's foreign waste ban on the global circular economy. Resources, Conservation and Recycling, 144(January), 252-255. https://doi.org/10.1016/j.resconrec.2019.01.004

Quynh, D. (2020). Đông Nam Á đối phó với bãi đổ rác khi Trung Quốc thực thi lệnh cấm nhập khẩu rác thải. $C V D, 4$.

TTXVN. (2022). Malaysia " đau đầu " với ngành tái chế rác thải bất hợp pháp. Bnews, 4.

Vuong, Q. H., et al. (2022). Covid-19 vaccines production and societal immunization under the serendipity-mindsponge-3D knowledge management theory and conceptual framework. Humanities and Social Sciences Communications, 9, 22. Retrieved from: https://www.nature.com/articles/s41599-022-01034-6

Vuong, Q.-H. (2021). Western monopoly of climate science is creating an eco-deficit culture. Economy, Land \& Climate Insight, 11, 1-9. https://elc-insight.org/western-monopoly-of-climat

Vuong, Q. H. (2018). The (ir)rational consideration of the cost of science in transition economies. Nature Human Behaviour, 2(1), 5. https://doi.org/10.1038/s41562-017-0281-4

Vuong, Q. H. (2021). The semiconducting principle of monetary and environmental values exchange. Economics and Business Letters, 10(3), 284-290. https://doi.org/10.17811/ebl.10.3.2021.284-290

Wen, Z., Xie, Y., Chen, M., \& Dinga, C. D. (2021). China's plastic import ban increases prospects of environmental impact mitigation of plastic waste trade flow worldwide. Nature Communications, 12(1), 1-9. https://doi.org/10.1038/s41467-020-20741-9 